\title{
Percutaneous coronary intervention in the elderly: current updates and trends
}

\author{
Mohammed J. Arisha1', Dina A. Ibrahim², Ahmed A. Abouarab³, Mohamed Rahouma ${ }^{3}$, Mohamed K. Kamel ${ }^{3}$, \\ Massimo Baudo ${ }^{3}$, Kritika Mehta ${ }^{3}$, Mario F. L. Gaudino 3 \\ 'Division of Cardiovascular Disease, University of Alabama at Birmingham, Birmingham, AL 35233, USA. \\ 2Department of Medicine, Brown University, Providence, RI 01912, USA. \\ ${ }^{3}$ Department of Cardiothoracic Surgery, Weill Cornell/New York Presbyterian Hospital, New York, NY 10065, USA.
}

Correspondence to: Dr. Mario F. L. Gaudino, Department of Cardiothoracic Surgery, Weill Cornell Medicine, 525 East 68 th St., Suite M 404, New York, NY 10065, USA. E-mail: mfg9004@med.cornell.edu

How to cite this article: Arisha MJ, Ibrahim DA, Abouarab AA, Rahouma M, Kamel MK, Baudo M, Mehta K, Gaudino MFL. Percutaneous coronary intervention in the elderly: current updates and trends. Vessel Plus 2018;2:14.

http://dx.doi.org/10.20517/2574-1209.2018.29

Received: 8 May 2018 Accepted: 5 Jul 2018 Published: 9 Jul 2018

Science Editors: Aaron S. Dumont, Alexander D. Verin Copy Editor: Jun-Yao Li Production Editor: Cai-Hong Wang

\begin{abstract}
Ischemic heart disease is the leading cause of death with acute coronary syndrome accounting for more than $30 \%$ of causes of mortality in the elderly population. The rate of growth of the older segment of the population has increased exponentially and will become more pronounced in the future. Historically, there has been a paucity of clinical trials investigating the challenges and outcomes of more invasive treatment strategies such as percutaneous coronary intervention $(\mathrm{PCl})$ for that very segment of the population. However, the safety, efficacy, and outcomes of $\mathrm{PCl}$ in the older population have started to receive more attention, leading to some changes in their trends. There are several factors that make interventional cardiologists more resistant to direct the elderly to $\mathrm{PCl}$. Most of these challenging factors, such as the complexity of coronary lesions, frailty, hematological and vascular changes, are discussed in this review. In addition. more advanced technologies have been introduced to $\mathrm{PCl}$ platform such as second-and thirdgenerations stents, several alternative approaches have been adopted like transradial approach and the usage of bivalirudin instead of heparin and GP Ilb/IIla inhibitor, and several imaging modalities have been optimized to assess patients' outcome and prognosis more accurately. Several recent studies have shown better results when these strategies are adopted. The most recent recommendations regarding performing $\mathrm{PCl}$ in the elderly are also discussed in this review.
\end{abstract}

Keywords: Percutaneous coronary intervention, coronary artery disease, acute coronary syndrome, coronary stents, angioplasty, elderly, old age patients, frail patients, high risk patients

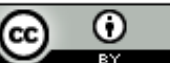

(C) The Author(s) 2018. Open Access This article is licensed under a Creative Commons Attribution 4.0 International License (https://creativecommons.org/licenses/by/4.0/), which permits unrestricted use, sharing, adaptation, distribution and reproduction in any medium or format, for any purpose, even commercially, as long as you give appropriate credit to the original author(s) and the source, provide a link to the Creative Commons license, and indicate if changes were made.

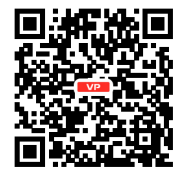




\section{INTRODUCTION}

Ischemic heart disease is one of the major challenges that encounter healthcare providers all over the world. It is considered the leading cause of death with acute coronary syndrome (ACS) accounting for more than $30 \%$ of causes of mortality in the elderly population (aged 65 years or older) ${ }^{[1]}$. The elderly group of population has grown substantially. For many reasons, the rate of growth has increased exponentially and will become more pronounced in the future, especially in the developed world. In 1970, the population aged 65 years and older constituted only $9.8 \%$ of the total population in the United States, however, in 2012 it increased to $13.7 \%$ and it is expected to exceed $20 \%$ by the year 2030 . Octogenarians and older populations constituted a smaller segment of only $3.7 \%$ comparing to their younger counterparts in 2012 but it is also expected to jump up to $3.9 \%$ and $5.4 \%$ by 2020 and 2030, respectively ${ }^{[2]}$. Despite the recent advancements that have been achieved in both clinical and interventional cardiology realms, the management of coronary artery disease (CAD) in the elderly is still a major concern, both for cardiac interventionists and surgeons. Historically, older patients often receive conservative management rather than invasive procedures and there is a paucity of clinical trials investigating the challenges and outcomes of more invasive treatment strategies for that very segment of the population. Therefore, this relative under-representation of elderly in clinical trials and the consequent lack of knowledge made many cardiology interventionists more reluctant to perform percutaneous coronary intervention (PCI) for very elderly patients which hinders their optimal evidence-based therapy ${ }^{[3]}$. Recently, safety and outcomes of PCI in the older population has started to receive more attention, therefore, changes in its trends have to be studied thoroughly. In this review, we discuss age and its impact on older patients' stratification and prognosis, the most relevant challenges that make PCI more difficult in this group of patients, recent changes in trends of PCI in the elderly, and the latest guidelines and recommendations.

\section{AGE AND PCl}

There is no specific age beyond which PCI cannot be performed, however, with increasing age less invasive therapy is usually preferred. In the literature, even a few centenarians underwent successful PCI procedures ${ }^{[4,5]}$. The oldest reported case was a 106-year-old lady who presented with inferior wall ST-segment elevation acute myocardial infarction (STEMI) ${ }^{[5]}$. It is also difficult to assign a clear-cut age threshold to classify patients based on their ages as risky $v s$. non-risky patients. However, according to the data from the Global Registry of Acute Coronary Events (GRACE), patients aged 75 years or more had more cardiovascular risk factors such as history of congestive heart failure (CHF), myocardial infarction (MI), hypertension, atrial fibrillation, diabetes mellitus, and stroke comparing to younger patients ${ }^{[3]}$. Also, patients aged 75 years and older were considered a special group in the American College of Cardiology Foundation/American Heart Association (ACCF/AHA) guidelines ${ }^{[6,7]}$. Thus, in this review, we define risky old patients as patients aged 75 or more.

Age of patients presenting with ACS has a significant prognostic value and it is considered the second most important predictor of mortality after Killip class as it has been shown that the in-hospital mortality risk of a patient with ACS increases by 1.7 fold for each 10 years and by 2 folds for each Killip class deterioration ${ }^{[8]}$. Risk stratification plays a crucial and decisive rule during the initial management of ACS patients, as it helps to determine the appropriate site of care and the intensity of therapy. Age among other patients' demographic characteristics profoundly affects this stratification as well as the initial estimate of death and/ or other cardiac events even before performing any physical examination or reviewing electrocardiograms (ECG) and laboratory results ${ }^{[6]}$. This is why, age is usually a vital criterion in several scoring systems that are used to estimate the in-hospital, 30 days, and even 1-year mortality rates of patients presenting with ACS and risk of complications as well. Among these scoring systems, the GRACE risk score ${ }^{[9,10]}$, the thrombolysis in myocardial infarction (TIMI) risk score ${ }^{[11,12]}$, and the "platelet IIb/IIIa in unstable angina: receptor suppression using integrilin therapy" (PURSUIT) risk score ${ }^{[13]}$. According to the GRACE score, age of more than 75 adds a mortality risk score of 73. For TIMI score, age of more than 65 adds a 5\% risk at 14 days of: all-cause mortality, new or recurrent MI, or severe recurrent ischemia requiring urgent revascularization. 
As far as the PURSUIT score, age of 70 or more adds a mortality only risk of 4 points and a risk of mortality and infarction of 11 points.

\section{PCI CHALLENGES IN OLDER POPULATION}

Providing proper management and rehabilitation for older patients could be very challenging. Certainly, this becomes more sophisticated if a more invasive procedure such as PCI is required. Factors that make interventional cardiologists more resistant to perform PCI for an elderly patient can be either general factors related to the patient's general status such as frailty, co-morbidities, functionalities of their cardiovascular and other systems or local factors related to coronary lesions such as the complexity of these lesions. Here, we discuss the most relevant factors in more details.

\section{FRAILTY AND MULTI-MORBIDITY}

Frailty is often defined as gradual insufficiency and regress of multiple body systems that eventually lead to an ultimate state of low reserve, functional/ cognitive decline, and inability to cope with different stressors. It is also considered by geriatricians to be a clinical syndrome that makes patients vulnerable to a variety of adverse outcomes ${ }^{[14]}$. Frailty becomes more apparent with aging, and unfortunately, even with the best healthcare and interventions provided to the elderly in order to support, improve, and maintain their quality of life, frailty is usually inevitable at a certain point of their age ${ }^{[15]}$. Based on the analysis of data from 4735 out of 5888 participants of the Cardiovascular Health Study (CHS), the mean ages of non-frail, intermediate state, and frail patients were 71.5, 73.4, and 77.2 years, respectively. The same study demonstrated a higher prevalence of cardiac risk factors such as CHF, history of angina, MI, peripheral vascular disease (PVD), and carotid stenosis in frail patients ${ }^{[16]}$. Some inflammatory markers such as C-reactive protein (CRP) and some clotting factors like factor VIII and fibrinogen were found to be in higher levels in frail patients compared to non-frail ones, suggesting that the high prevalence of some PCI adverse outcomes such as thrombotic complications in the aging frail population can be explained by an inflammatory process yet to be understood $^{[17]}$. With aging, a variety of cardiac and non-cardiac morbidities usually exist concurrently with the patients' coronary problems which makes it even more difficult for them to suit such procedures and to overcome any ominous adverse event. In the United States, the prevalence of cardiac diseases, hypertension, stroke, chronic obstructive pulmonary disease (COPD), kidney diseases, arthritis, and a lot of cancers is higher among the population aged 75 and older more than any other age group ${ }^{[18]}$.

\section{POLYPHARMACY}

With the increased prevalence of different morbidities among older patients, being on multiple medications at the same time is an expected consequence. Polypharmacy is more pronounced in the geriatric population and it makes patients more prone to many cardiac events which makes deciding PCI for them more unlikely. Data collected from 384 old frail patients participated in the Geriatric Evaluation and Management (GEM) Drug Study revealed that more than $40 \%$ of the participants were on 5 to 8 different medications and more than $37 \%$ had even more than 8 medications at the time of their discharge ${ }^{[19]}$. In a prospective cohort study on old aged men with a mean age of 77 years, polypharmacy was associated with poor cardiovascular events such as MI and stroke with a statistically significant hazard ratio of 1.09 (95\% CI: 1.06-1.12) $)^{[20]}$. In addition to that, many factors associated with advanced age such as the decrease in renal function, low glomerular filtration rate, decreased liver mass and blood flow can alter many drugs pharmacokinetics and reduce their hepatic and renal elimination predisposing patients to more adverse events ${ }^{[21]}$. Another challenge that could be faced during dealing with any elderly who needs PCI, is adjusting the dose of their cardiac medications as changes in water-fat balance in their body composite affect drugs distribution and dosing to a significant extent. Older patients have a lower total body water that leads to a lower volume of distribution and a higher serum level of water soluble medications such as digoxin that necessitate reduction of its loading 
dose. In contrary, relative increase in total body fat resulted from reduction of adipose-free body mass in elderly people leads to increased volume of distribution of fat-soluble medications such as lidocaine and prolongation of their half-life ${ }^{[2]}$. Another issue is that the recommended use of dual antiplatelet therapy (DAPT) in the elderly PCI patients has many additional complications which may influence the choice of the stent and the mode of management of these patients, including; higher risk of bleeding, need for concomitant warfarin therapy for atrial fibrillation, the increased likelihood of having future non-cardiac surgery, and the increased risk of falls ${ }^{[13]}$. When added to therapy, anti-coagulants dosing is also altered with advanced age. It has been shown that old age is usually associated with a lower warfarin maintenance dose with patients aged 80 to 89 years usually requiring only half of a total weekly dose (TWD) of warfarin compared to patients aged between 20 and 59 years ${ }^{[22]}$.

\section{HEMATOLOGICAL AND VASCULAR CHANGES}

A lot of changes that occur with aging may cause the elderly to paradoxically experience hemorrhagic or thrombotic complications after PCI. Age is a significant independent predictor of major bleeding in ACS patients who had PCI and it is associated with higher in-hospital mortality rates ${ }^{[23]}$. Case fatality has been shown to be more than $18 \%$ in patients who experienced any major bleeding following PCI while $5 \%$ in patients without major bleeding ${ }^{[23]}$. Interestingly, thrombotic complications such as stent thrombosis and restenosis occurred more frequently with advanced age as well. In a previous study, $47 \%$ of all patients aged 75 years and older who had PCI with stenting experienced a 50\% or more restenosis at the stent site or adjacent to it compared to only $28 \%$ in younger patients. Also, older patients experienced more diffuse restenosis ( $1 \mathrm{~cm}$ or more in length) than their younger counterparts ${ }^{[24]}$. Increased risk of bleeding in elderly can be explained by several hematological alterations such as higher level of tissue plasminogen activator $(\mathrm{tPA})^{[25]}$, lower platelets aggregation ${ }^{[26]}$, and the presence of more advanced and complicated vascular disease with more local changes, more atherosclerosis and hypertension ${ }^{[23]}$. In contrary, older people have a higher blood viscosity, higher activity of several coagulation factors, and a lower fibrinolytic activity as it has been proven that plasminogen activator inhibitor (PAI-1) level increases with age ${ }^{[27,28]}$. These changes cause a prothrombotic state in older patients that potentially increases risk of post-PCI thrombotic complications as well. In addition, aging is associated with impairment of vascular structure and endothelial function caused by several interacting histological and molecular alterations such as increased collagen content, smooth muscle changes, and altered composition of the extracellular matrix of the arterial wall. This can lead to a gradual decrease in elastic fibers, arterial wall rigidity, and increased risk of atherosclerosis and arterial thrombosis ${ }^{[28]}$. Many PCI-related vascular complications such as large hematomas in femoral regions, pseudoaneurysms, and arteriovenous fistulas have been also associated with advanced age ${ }^{[29]}$. Also, the gradual impairment of endothelial cells function that occur with aging leads to lower production of nitric oxide and prostacyclin which play an important role in promoting vasodilatation as well as preventing platelets aggregation ${ }^{[28,30]}$.

\section{CORONARY LESIONS COMPLEXITY}

Older patients usually have more complex and advanced coronary lesions which make PCI procedures more difficult with a higher risk of complications and a lower chance of procedure success. Batchelor et al. ${ }^{[31]}$ compared the angiographic characteristics of 7472 octogenarian patients with 102,236 younger others undergoing PCI. Older patients had more left main coronary artery (LMCA) and proximal left anterior descending (LAD) lesions than patients aged 79 and younger, $7.3 \%$ vs. $5.7 \%(P<0.01)$ and $24 \%$ vs. $20 \%(P<0.01)$, respectively. In a different sample of patients, the angiographic characteristics based on the modified ACC/AHA criteria revealed that 863 out of 2551 (33.8\%) patients aged less than 75 years had coronary lesions of type B1 or less, in contrast to only 37 out of $137(27 \%)$ patients aged 75 years or more $(P=0.002)$. On the other hand, lesion types B2 and C were more prevalent in older than younger patients, $72 \% v s .65 \%(P=0.002)$, respectively ${ }^{[24]}$. Older patients had a higher number of affected vessels as well, as $55 \%$ of patients aged 75 or more had 3 diseased coronary 
vessels compared to only $24 \%$ of younger patients $(P=0.0001)$. Also, $22 \%$ of older patients $v s .38 \%$ of their younger counterpart had only 1 diseased vessel $(P=0.0001)^{[24]}$. The Synergy between Percutaneous Coronary Intervention with TAXUS and Cardiac Surgery (SYNTAX) score has been used to predict clinical outcomes in patients undergoing PCI especially those with LMCA lesions and/or multivessel coronary disease based on their lesions complexity ${ }^{[32]}$. More recently, this scoring system has been integrated with some independent clinical variables such as the patient's age, creatinine serum level, and left ventricular ejection fraction (LVEF) to obtain the clinical SYNTAX score $(\mathrm{CSS})^{[33]}$. Both scoring systems have been shown to be valid in risk stratification and early mortality prediction among older patients with ACS undergoing PCI. While the SYNTAX score did not predict long-term clinical outcomes, the CSS was useful in predicting the 1-year major adverse cardiac and cerebrovascular events, reflecting the potentially significant impact of the patient's clinical and demographic factors such as their ages on their clinical outcomes ${ }^{[34]}$. Previous studies have also shown that age is significantly associated with increased coronary artery calcium score ${ }^{[35,36]}$. Calcification of the coronary system is associated with coronary artery disease (CAD) and coronary artery calcium content is highly associated with increased cardiovascular events ${ }^{[36]}$.

\section{PCI ADVERSE EVENTS}

As a result of the previously mentioned factors, PCI outcome is expected to be worse in the older patients comparing to the general population. Indeed, the most devastating outcome would be death. Although studies have demonstrated reasonable short and long-term PCI outcomes in the elderly, the in-hospital, 30 days, and even 1 to 5 years follow-up all-cause mortality rates are still higher ${ }^{[37-39]}$. Aside from death, there is a higher chance that older frail patients experience a variety of complications that can occur consequently as a result of this procedure and affect patients' clinical outcome and quality of life than other younger patients ${ }^{[40]}$. Many cardiac complications have been described such as cardiogenic shock, acute MI, acute ventricular septal rupture (VSR), iatrogenic coronary dissection, coronary perforation, and stent thrombosis. Other non-cardiac complications have also been reported such as hemorrhage, acute kidney injury, stroke, and access site complications like femoral or radial dissection and/or hematoma ${ }^{[41,42]}$. Major bleeding is one of the complications associated with unfavorable clinical outcome. Pooled data from 5 different trials that participated in the RESOLUTE study program and included 5130 patients undergoing PCI with the resolute zotarolimus-eluting stent showed that rates of some complications such as MI and repeat revascularization in 1675 patients aged 70 years or older $(33 \%)$ were similar to those of younger participants, however, significant bleeding events occurred more frequently among older population. In-hospital and 1-month follow-up bleeding complications occurred in $1.3 \%$ and $1.6 \%$ of patients aged 70 years or older, and $0.3 \%$ and $0.5 \%$ of younger participants $(P=0.009$ and 0.014$)$, respectively. Death occurred in $26 \%$ of old patients who experienced bleeding events with a median time of 21 days between the bleeding event and time of death ${ }^{[38]}$. Another study showed an increase of $2.4 \%$ in over-all rates of bleeding events among patients undergoing PCI in their octogenarian years than younger patients ${ }^{[37]}$. Many different bleeding complications have been reported to be associated with PCI such as, access site bleeding, pericardial bleeding that can lead to tamponade, retroperitoneal bleeding, and gastrointestinal bleeding as well ${ }^{[37]}$. Beside age of the patient, many other variables have been proven to be an independent predictor of unfavorable outcome in the elderly undergoing PCI. Reduced cardiac function with left ventricular ejection fraction (LVEF) lower than $40 \%$, Killip class of 3 or worse, cardiogenic shock, and hypotension with systolic blood pressure (SBP) lower than $100 \mathrm{mmHg}$ have all been identified as independent predictors of an increased risk of 1-year mortality ${ }^{[43]}$. Also, the activity of daily living (ADL) of old age patients after PCI can be used to predict mortality. ADL assessment by Barthel index (BI) at the time of admission and discharge has been investigated by Higuchi et al. ${ }^{[4]}$ to predict 1-year mortality in very old patients undergoing PCI for ACS. They have shown that lower BI at the discharge of the patient can be a predictor of higher mortality in patients aged 85 years and older with each 5 unites decrease in BI being associated with 1.1 fold increase in 1-year mortality risk. 
Table 1. Comparison of the predictive value of the CHA2DS2VASc score for stroke and atrial fibrillation in elderly patients based on gender

\begin{tabular}{lccccc}
\hline $\begin{array}{l}\text { Elderly }> \\
\text { 75 years old }\end{array}$ & $\begin{array}{c}\text { Baseline score } \\
\text { according to age } \\
\text { and gender only }\end{array}$ & $\begin{array}{c}\text { Score after adding } \\
\text { a single additional } \\
\text { risk factor }\end{array}$ & $\begin{array}{c}\text { Target high risk } \\
\text { score for atrial } \\
\text { fibrillation }\end{array}$ & $\begin{array}{c}\text { Stroke risk (\%) at } \\
\text { baseline score }\end{array}$ & $\begin{array}{c}\text { Stroke risk (\%) } \\
\text { after adding a } \\
\text { single additional } \\
\text { risk factor }\end{array}$ \\
\hline Male & 2.0 & $3.0-4.0$ & $\geq 3.0$ & 2.2 & $3.2-4.0$ \\
possible score & 3.2 & $4.0-6.7$ \\
\hline
\end{tabular}

Aside from this, the $\mathrm{CHA}_{2} \mathrm{DS}_{2} \mathrm{VASc}$ score ${ }^{[45]}$ is a recognized predictor of the risk of having cerebrovascular episodes. Patients aged 75 or more are assigned 2 on the scale, making the elderly patients more likely to end up with higher scores. Adding the factor of gender, elderly females have a risk of 3 at baseline without adding the risk attributed to the other comorbidities on the scale and the PCI procedure. Interestingly, CHA2DS2VASc score of 2 or more was also found to be predictive of atrial fibrillation after cardiac procedures $^{[46]}$. Table 1 summarizes the significance of CHA2DS2VASc score in predicting stroke and atrial fibrillation in the elderly population.

\section{PCI TEMPORAL TRENDS}

Historically, there have been a lot of variations in the reported data regarding procedure outcomes and mortality rates among the older population undergoing PCI. Some of the papers published in the late eighties through nineties showed the success rate of percutaneous transluminal coronary angioplasty (PTCA) in the elderly to be approximately $82 \%-84 \%$ and highly variable mortality rates ${ }^{[77-49]}$, however, Both success and mortality rates have varied a lot in other papers published in the same era. Kern et al ${ }^{[50]}$ reported in 1988 a clinical success rate of a $67 \%$ in a group of 21 patients who had undergone PTCA in their octogenarian years. After that, a clinical success rate of $57 \%$ was reported in 43 patients aged 75 years and older by other investigators $^{[51]}$. In contrary, Jeroudi et al. ${ }^{[52]}$ demonstrated PTCA angiographic and clinical success in 50 and 49 patients, respectively out of 54 octogenarian patients (93\% and 91\%, respectively). Procedure success has differed considerably between septuagenarians, octogenarians and older participants in the same group of old aged patients as it was $85 \%, 73 \%$, and as low as $50 \%$ for patients aged 70 to 74,75 to 79 , and 80 years and older ${ }^{[49]}$. Also, procedural mortality rate varied and reached up to $19 \%$ during the same era ${ }^{[50,53]}$. Many cardiac and non-cardiac complications were reported and occurred in more than third of the participants in some of the previous studies ${ }^{[47,50]}$. Although PCI has been proven to be feasible in the older population, the previous rates of success, procedural mortality, and consequent complications were unacceptable to many healthcare providers which created a high level of prudence and caution before deciding to perform PCI on such patients. Over years, several advanced technologies have been introduced, useful cardiac imaging modalities have been more available, less invasive approaches and protocols have been investigated to be adopted, and the operator techniques have been improved. As a result, a less conservative trend in performing more invasive procedures on older patients has gradually appeared. In a cohort of 31,758 patients who had undergone PCI between 2000 and 2007, the incidence of PCI in patients aged 75 and older has increased from 56/100,000 in 2000 to $216 / 100,000$ in $2007^{[54]}$. PCI share of older patients has increased even in the very old segment such as the nonagenarians. Among 26,696 PCI performed over 11 years, only 177 were performed on nonagenarians, however, the prevalence of $\mathrm{PCI}$ in this very subgroup of patients was $0.17 \%$ in 2004 and increased to $1.22 \%$ in $2014^{[41]}$. Recent studies have also shown some changes in PCI mortality and complications trends. Generally, the success rate has improved, mortality and complications risk started to approach those of younger population. In a very recent study that was published in 2018, the outcomes of PCI in octogenarians and younger patients using second-generation cobalt-chromium everolimus-eluting stents were practically the same ${ }^{[42]}$. Angiographic success was $98.4 \%$ in octogenarians and $98 \%$ in younger participants $(P=0.85)$. A lot of both in-hospital and 1-year follow-up post PCI-complications were also comparable between the 2 groups. In-hospital major bleeding events and cerebrovascular accidents have not occurred in either of the 2 groups, however, acute kidney injury occurred more frequently in octogenarians, 
3.7\% vs. $1.5 \%(P=0.58)$. One-year follow-up myocardial infarction occurred in $1.9 \%$ and $1.5 \%(P=1.00)$ in octogenarians and younger patients, respectively. Interestingly, some complications occurred less frequently with the octogenarian group than its younger counterpart such as in-hospital subacute stent thrombosis and 1-year follow-up cerebrovascular accidents, $0 \%$ vs. $1.5 \%(P=1.00)$ and $1.9 \%$ vs. $2.3 \%(P=1.00)$, respectively. Although recent studies have also shown some variations in their results, in 2017 many papers have reported relatively high PCI success rates in the elderly that ranged approximately from $75 \%$ to $95 \%{ }^{[55-57]}$. Many of these recent papers have reported better mortality and some complications trends than before ${ }^{[2,55,58,59]}$. Some of them even reported similar rates of major adverse events in both young adults and elderly in more critical situations such as patients with atrial fibrillation (A-fib) undergoing PCI. Lahtela et al.$^{[0]}$ conducted a post-hoc analysis of $925 \mathrm{~A}$-fib patients' data from the atrial fibrillation undergoing coronary artery stenting (AFCAS) registry and showed comparable incidence of in-hospital and 1-month major adverse cardiac and cerebrovascular events (MACCE) in octogenarian patients and younger ones ${ }^{[6]}$. It is worth mentioning that some recent studies still demonstrate a quit high adverse outcomes rates including in-hospital mortality that reached up to $20 \%{ }^{[62,63]}$.

\section{PROCEDURAL ASPECTS IN ELDERLY}

Many aspects regarding PCI procedure in the elderly can be modified, adjusted, and tailored in order to make this very segment of the population more suitable for such a procedure and to render the interventional cardiologists more comfortable to decide to perform these procedures in older patients. Among these aspects are the length of procedure, the volume of contrast agent, the access site, the nature of the intervention, the type of the stent, and the length of hospital stay.

\section{ACCESS SITE}

Generally, transfemoral approach has been the traditional standard of care for many years, however, previous studies have shown that the newer transradial route is superior to the transfemoral one as the former has been associated with better results and lower rates of complications and it has been increasingly used instead of the femoral access in the general population ${ }^{[64,65]}$. In terms of the use of this approach in the elderly undergoing PCI, the net benefit is still not totally clear. The differences between both approaches in older patients have been reported in some studies and they demonstrated a high percentage of old patients' PCI in whom transradial approaches have been performed. The transradial access has been used in up to almost $80 \%$ of old aged patients of some cohorts ${ }^{[6,667]}$. In a 1:1 propensity score analysis of data from 1098 patients aged 75 years and older who underwent PCI with either transfemoral or transradial approach, lower rates of in-hospital and 1-year follow-up major adverse clinical events, in-hospital MI, access site complications, and major bleeding were associated with the use of transfemoral access ${ }^{[6]]}$. Other adverse clinical outcomes occurred less frequently with the transradial approach such as in-hospital death and target vessel revascularization but there were no significant statistical differences between the two groups. The same study demonstrated comparable rates of non-access site related major bleeding events with both approaches ${ }^{[6]}$. In contrary, some recent studies have also shown a very low usage of the transradial approach with the elderly. Among 1945 octogenarian patients of the Korea Acute Myocardial Infarction Registry, 1609 participants $(82.7 \%)$ underwent PCI using the transfemoral approach and only 336 (17.3\%) with the transradial approach. Nevertheless, using the transradial access has been found to be a predictor of a lower in-hospital mortality in the same group of patients ${ }^{[68]}$. In the same study, intra-aortic balloon pump (IABP) had to be used in $103(6.4 \%)$ patients in the transfemoral group vs. only 5 (1.5\%) patients of the transradial group. Access site can also affect other variables like the time and volume of the contrast agent and the length of hospital stay, as the transradial approach was shown to be associated with a shorter hospital stay and a lower dose of contrast dye comparing to transfemoral one among older patients ${ }^{[6]}$. However, several other studies showed comparable contrast volume and procedure time with both approaches ${ }^{[1,66]}$. In terms of procedural success, several studies demonstrated almost similar PCI success in elderly using 
both approaches ${ }^{[41,68]}$, however, many investigators believe that older population can benefit more from the transradial approach and it should be used more often with the elderly undergoing PCI.

\section{TYPE OF STENT}

As it was discussed above, the coronary lesions in the elderly tend to be more complex and extensive which may render them suitable only for plain old balloon angioplasty (POBA) due to a failure of stent delivery, or inability to stent lesions in distal or small diameter vessels ${ }^{[43]}$. On the other hand, stenting technology has revolutionized during the last era. Since their first successful clinical application in 2002, drug-eluting stents (DES) have been utilized more frequently comparing to bare metal stents (BMS) as lower rates of stent restenosis, major adverse cardiac events, and revascularization of target lesions have all been associated with the use of DES ${ }^{[69]}$. The second-generation DES even have a better stent design than the first-generation ones with a thinner strut and more biocompatible polymers which lead to a higher efficacy and lower complications ${ }^{[0,71]}$. However, the use DAPT for at least 1 year to prevent stent thrombosis associated with DES raises concerns regarding increased risk of bleeding especially in populations with an already high risk of bleeding such as the elderly ${ }^{[70]}$. Although some studies suggested reducing the DAPT to 3-6 months without an increase in the risk of many adverse clinical events ${ }^{[72]}$. Recent data still suggesting under-utilization of DES in elderly patients undergoing PCI with stenting ${ }^{[70]}$. The characteristics and clinical outcomes of 1564 high bleeding risk old patients aged 75 years or older who participated in the LEADERS FREE trial and underwent PCI with the deployment of either polymer-free DES or similar BMS and only 1 month of DAPT were analyzed ${ }^{[73,74]}$. They showed a high yet similar bleeding rate in the 2 groups. However, rates of mortality, stent thrombosis, MI, and target lesion revascularization were lower in patients underwent stenting with DES reflecting superior safety and efficacy benefits compared to $\mathrm{BMS}^{[74]}$. In addition to that, major bleeding rates did not differ significantly between octogenarian patients who received PCI with BMS and only 1-month mandatory DAPT and others with DES and a 1-year course of DAPT in the XIMA trial ${ }^{[75]}$. Also, compared to the first-generation DES, the use of second-generation DES has been associated with better outcomes in the older population, as the latter has been associated with a lower risk of MI in the following year among patients aged 70 years or older with a hazard ratio of 0.40 (95\% CI: 0.19-0.82); $P=0.012^{[58]}$. Most recently, the SENIOR trial demonstrated lower rates of the 1-year all-cause mortality, MI, stroke, and revascularization in elderly patients who underwent PCI and received third-generation DES with bioabsorbable polymer and a short-term DAPT compared to those who received $\mathrm{BMS}^{[76]}$. In the same trial, the duration of DAPT was decided before patients' random assignment to the two different types of stents and it was recommended to be 1 month for stable patients and 6 months for unstable ones, however, the bleeding complications were comparable in both study arms.

\section{BLEEDING AVOIDANCE STRATEGIES}

With peri-procedural bleeding being one of the most concerning topics regarding PCI in elderly patients ${ }^{[23]}$, several approaches and strategies have been developing aiming at reducing the amount of blood loss and improving the safety and efficacy of these procedures in populations of high risk. Bleeding avoidance strategies (BAS) include the usage of vascular closure devices (VCD), transradial approach instead of the transfemoral, and bivalirudin instead of heparin and GP IIb/IIIa inhibitor ${ }^{[77]}$. Previous data showed that BAS have been associated with lower risk of Peri-PCI bleeding, nevertheless, these strategies are underutilized among patients with higher risk of bleeding suggesting what we call "risk-treatment paradox" ${ }^{\text {"[77,78] }}$. Khambatta et al..$^{[79]}$ evaluated the data of 124,606 patients with different ages who underwent PCI over a period over 4 years to study the effect of BAS on rates of bleeding and other variables in different age groups. They have demonstrated a lower incidence of bleeding with the utilization of BAS with an adjusted odds ratio of 0.982 (95\% CI: 0.980-0.984) compared to those without BAS usage in all age groups even patients older than 80 years. BAS was also associated with lower in-hospital mortality with an adjusted odds ratio of 0.993 (95\% CI: 0.992-0.994). Interestingly, although the overall usage of BAS has been improving in all age groups over the whole study period, their utilization was still less frequent in old age patients ${ }^{[79]}$. 


\section{TIME OF INTERVENTION}

There are some conflicting data regarding the perfect timing of PCI in patients presenting with STEMI, however, several previous studies have shown that shorter door-to-balloon time (DTBT) is associated with better outcomes and many investigators believe that attempts to avoid any DTBT delay should be adopted regardless the patient's baseline risks ${ }^{[80,81]}$. Optimally, reperfusion should be attained within the recommended 90-minute window, however, many patients still undergo PCI beyond this time limit ${ }^{[82]}$. DTBT has been shown to be longer among older populations compared to their younger counterparts in several recent studies ${ }^{[57,62,79]}$. The median DTBT in a cohort of 2972 consecutive patients who underwent primary PCI for STEMI was 70, 76, and $80 \mathrm{~min}$ for patients aged $<75,75$ to 84 , and $\geq 85$ years, respectively $(P<0.001)^{[57]}$. Being an old age patient per se, has been shown to be an independent predictor for the doorto-balloon delay ${ }^{[83]}$. Other predictors have been described such as non-daytime presentation, the absence of typical chest pain, the need for hospital transfer, female sex, and non-white race ${ }^{[83]}$. Elderly patients with ACS often present with non-specific and atypical symptoms like nausea, vomiting, diaphoresis, and dyspnea. Chest pain occurs only in approximately $40 \%$ of patients older than 85 years $^{[84]}$. Also, the higher prevalence of left bundle branch block (LBBB) in older population patients makes the electrocardiographic diagnosis of STEMI more difficult ${ }^{[84]}$. These unusual presentations of ACS and time-wasting factors may cause some sort of delayed diagnosis and management which consequently leads to worse outcomes in elderly undergoing PCI that must be investigated thoroughly in the near future.

\section{AUXILIARY CARDIAC IMAGING UTILIZATION}

Over the last years, we have witnessed dramatic advancements in the field of cardiac imaging. Several imaging modalities such as transesophageal echocardiography (TEE), cardiac computed tomography (CT), cardiac magnetic resonance imaging (CMR), and intravascular ultrasonography (IVUS) have been evolving and their usefulness in the diagnosis and assessment of a variety of clinical and/or surgical situations has been studied ${ }^{[85,86]}$. We believe that the optimal utilization of several cardiac imaging modalities can provide an additive benefit to the patients undergoing PCI, especially among older populations. Moreover, the integration of clinical and imaging data can assess patients' prognosis and predict their clinical outcomes. It also can define and classify several procedural complications and guide healthcare providers to decide whether to adopt a conservative management strategy or to proceed with more aggressive options ${ }^{[87]}$. For instance, intra-operative TEE has been used to guide several procedures in the catheterization theater and it provided useful assessments to some age-related PCI complications such as iatrogenic aortic intramural hematomas and helped to assess the patient's outcome and to decide the best management ${ }^{[87]}$. Furthermore, with the latest developments of three-dimensional TEE, more accurate intra-operative images of stent scaffolds can be obtained which enabled some investigators to more confidently diagnose and assess some PCI complications like LMCA stent protrusion and migration ${ }^{[88,89]}$. Thus, and as we mentioned above, with the older populations usually having more frequent LMCA lesions than younger patients, they can benefit from this modality. Also, IVUS and optical coherent tomography (OCT) have been shown to be useful in the qualitative assessment and preparation of LMCA lesions and in stent sizing and optimization as well ${ }^{[00,91]}$. In addition to that, post-PCI risk stratification has been proven to be helpful in evaluating STEMI patients' prognosis. The use of CMR during the hyperacute phase of STEMI after primary PCI has been shown to be safe and feasible ${ }^{[92]}$. Although the value of most of these imaging modalities in the elderly undergoing PCI as a separate high-risk group has not been investigated in large scales studies, many of them may provide useful contributions during the management of these patients in the future.

\section{DIFFERENT INDICATIONS OF PCI IN ELDERLY}

It has been shown that PCI was indicated for older population in a wide spectrum of different clinical situations with variable disease severities, from primary PCI in unstable old patients with STEMI and urgent PCI for those presenting with non-STEMI and unstable angina pectoris to elective PCI for old patients with stable CAD. Many previous studies have demonstrated that older patients who underwent PCI for unstable 
ACS constituted the bigger portion of the total elderly underwent PCI. Among 102 CAD patients aged 85 years and older, PCI was indicated in an ACS setting in $72.6 \%$ of them and only $24.5 \%$ of PCIs were performed for patients with stable angina ${ }^{[93]}$. In another cohort, 93\% of 177 PCI performed on nonagenarians were indicated in ACS settings and only $7 \%$ were elective $\mathrm{PCI}^{[41]}$. It is worth mentioning that clinical presentation and PCI indication are considered significant determinants of post-PCI clinical outcomes. As it has been shown that short and long-term clinical outcomes are usually superior in older patients who underwent PCI for stable CAD compared to unstable patients of the same age ${ }^{[93,94]}$. Among 102 PCI performed for a variety of indications in very old patients, aged $\geq 85$ years, there were 4 in-hospital deaths, all of them were patients presented to PCI due to acute STEMI. However, there were no deaths among very old patients from the same age group in whom PCI was indicated for stable coronary syndromes, post-STEMI, and other indications ${ }^{[93]}$. Teplitsky et al. ${ }^{[95]}$ reported a zero percent cumulative mortality rate at 6-month after elective PCI performed for nonagenarian patients with stable CAD. The 6-month cumulative mortality rate in patients underwent emergent PCI for clinically unstable ACS was $23 \%$ in the same study.

\section{PCI AMONG OTHER REVASCULARIZATION AND REPERFUSION STRATEGIES IN ELDERLY}

Generally, PCI is the most commonly used reperfusion strategy among all age group ${ }^{[96]}$. In terms of revascularization in older patients with CAD, a variety of strategies have been utilized, from conservative management with no revascularization at all to the most invasive surgical revascularization. However, the decision to choose the best reperfusion strategy for this high-risk group of patients has never been simple. Peiyuan et al. ${ }^{[97]}$ have compared the clinical outcomes of 3 groups of 3082 STEMI patients aged 75 years and older. Reperfusion by PCI was performed in 1000 patients, fibrinolysis was administrated to 160 patients, and the third group of 1922 patients did not have reperfusion therapy. PCI group had a significant lower mortality rates than fibrinolysis and no reperfusion groups of $7.7 \%, 15 \%$, and $19.9 \%$, respectively, $P<0.001$. Several adverse outcomes such as recurrent MI and MI-related complications like heart failure and cardiac arrest occurred less frequently in PCI group. Other previous studies from different populations have demonstrated better clinical outcomes in patients underwent PCI compared to those whom received fibrinolysis in all age groups including the elderly ${ }^{[98,99]}$. A meta-analysis of 22 randomized trials that included 6763 patients, also showed higher death and adverse outcomes rates of patients whom received fibrinolysis compared to primary PCI group among all ages except patients aged 50 years and younger ${ }^{[99]}$. Another strategy that involves combining fibrinolysis to urgent PCI can be potentially beneficial for elderly patients with ACS. The pre-hospital administration of a reduced-dose fibrinolytic agent before urgent PCI, termed FAST-PCI, showed better 30-day mortality rates than primary PCI alone, $4.2 \%$ vs. $18.1 \%$, respectively, $P<0.01$ in STEMI patients aged 75 years and older without an increase in rates of major bleeding events, stroke, or reinfarction ${ }^{[100]}$. Despite that many health care providers are still hesitant to direct old patients toward PCI, it has been shown that with aging, the frequency of PCI increases and that of coronary artery bypass grafting (CABG) decreases. Nicolini et al. ${ }^{[101]}$ compared the clinical outcomes and adverse events between PCI and CABG in a cohort of patients aged 80 years and older with multivessel disease or LMCA lesions. PCI was performed in 947 patients, while 441 underwent CABG. It is worth mentioning that, all nonagenarian patients included in the PCI group. Although the 1-month mortality rates of both study arms were comparable, many adverse outcomes were more frequent among patients who underwent PCI in the follow-up period such as cardiac mortality, MI, and target vessel revascularization. In another larger cohort of 10,141 patients aged 85 years or older with ACS and multivessel CAD, CABG was more frequently performed compared to PCI, and it was associated with better survival and freedom from composite morbidity at 3 years follow-up ${ }^{[102]}$. Thus, it appears that CABG is still the best strategy of revascularization in patients with multivessel disease or LMCA lesions even in elderly.

\section{RECOMMENDATIONS}

Several foundations and societies such as the ACCF, AHA, European Society of Cardiology (ESC), and the Society for Cardiovascular Angiography and Interventions (SCAI) have tried to adopt some guidelines and 


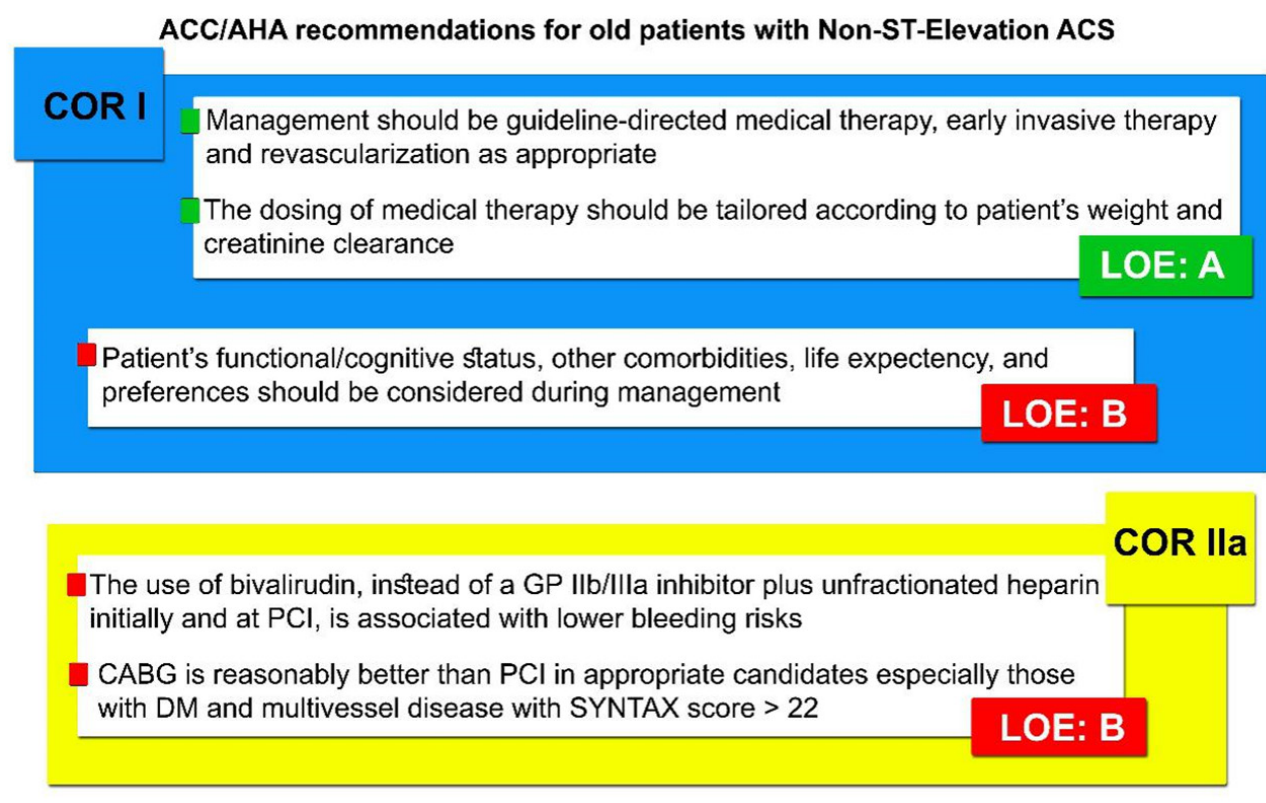

Figure 1. Summary of the 2014 AHA/ACC recommendations for the management of old patients ( $\geq 75$ years of age) with non-STelevation acute coronary syndromes. ACC: American College of Cardiology; AHA: American Heart Association; ACS: acute coronary syndrome; CABG: coronary artery bypass graft; COR: class of recommendation; LOE: level of evidence; DM: diabetes mellitus; PCl: percutaneous coronary intervention

recommendations based on the latest available clinical trials and observational studies in order to make the decision of performing PCI on older patients clearer and more evidence-based. The management of older population with CAD should be patient-centered and the decision whether to direct the patient toward reperfusion therapy or to adopt a less invasive and more conservative management should not be taken solely based on the patient's age. On the other hand, the patient's preferences, life expectancy, all his other co-morbidities, and functional status should be considered before denying or recommending PCI. A report from the ACCF, AHA, and SCAI stated that the PCI clinical benefits in younger and older population are comparable. However, the increased risk of some adverse outcomes in elderly like bleeding events and stroke should be taken into consideration ${ }^{[103]}$. The latest ESC guidelines for management of patients presenting with acute STEMI have also emphasized maintaining a high level of suspicion when dealing with any elderly presenting with atypical symptoms to avoid any delay in the diagnosis and reperfusion therapy ${ }^{[104]}$. Primary PCI should not have an upper age limit and any patient can be qualified for PCI based on his individual circumstances. The transradial approach was also recommended whenever it is possible in these patients. In addition, dosing of thrombolytic therapy should be adjusted carefully according to the patients' kidney function, other medications, and comorbidities. The ACCF and AHA have also recommended the use of bivalirudin, instead of a GP IIb/IIIa inhibitor plus unfractionated heparin, both initially and at PCI in elderly presenting with non-ST segment elevation ACS, as the former is associated with lower bleeding risks. However, the dosing of all the medical therapy must be modified according to the patients' body weight and creatinine clearance ${ }^{[6]}$. They have also stated that CABG can be preferred over PCI for appropriate candidates, especially those with diabetes mellites and multivessel disease with SYNTAX score of more than 22 [Figure 1].

\section{CONCLUSION}

There are several factors that render PCI a more challenging procedure among the elderly such as more complex coronary lesions, co-morbidities, frailty, and hematological alterations. Historically, PCI clinical outcomes have been demonstrated to be worse among older populations compared to their younger counterparts. Moreover, the participation of the elderly in the clinical trials that investigated different aspects of PCI has been markedly under-represented which created a vague state of decision making capability that 
consequently could hinder the optimal treatment for many old patients. Recently, more advanced technologies have been introduced to interventional cardiology platforms, a variety of medical therapy options have been available, less invasive PCI approaches have been adopted, more advanced cardiac imaging modalities have been improving, and more attention to elderly undergoing PCI has been given. Although that PCI mortality rates are still practically higher among the elderly, many recent studies demonstrated that PCI is safe and effective for this segment of the population and some adverse clinical outcomes became similar to those occurring in younger patients. Thus, the decision to perform PCI should not merely rely on the patient's age. Instead, many other considerations should be taken into account such as the patient's functional and/ or cognitive status, preferences, co-morbidities, current medications, and life expectancy. In addition, more elderly must be a part of the future clinical trials and the safety and efficacy of all the available as well as the emerging less invasive PCI strategies have to be investigated more thoroughly in order to provide a clearer knowledge regarding the optimal utilization of PCI among the elderly.

\section{DECLARATIONS}

\section{Authors' contributions}

Design: Arisha MJ, Rahouma M, Baudo M

Organization of the manuscript: Rahouma M, Baudo M

Literature search: Arisha MJ, Ibrahim DA, Abouarab AA, Mehta K

Manuscript writing: Arisha MJ, Ibrahim DA, Abouarab AA, Kamel MK

Figures arrangement: Arisha MJ, Kamel MK

References arrangement: Mehta K

Read and approved the final manuscript: Ibrahim DA, Rahouma M, Baudo M, Gaudino MFL

\section{Availability of data and materials}

Not applicable.

\section{Financial support and sponsorship}

None.

\section{Conflicts of interest}

All authors declare that there are no conflicts of interest.

\section{Ethical approval and consent to participate}

Not applicable.

\section{Consent for publication}

Not applicable.

\section{Copyright}

(c) The Author(s) 2018.

\section{REFERENCES}

1. Alexander KP, Newby LK, Cannon CP, Armstrong PW, Gibler WB, Rich MW, Van de Werf F, White HD, Weaver WD, Naylor MD. Acute coronary care in the elderly, part I: non-ST-segment-elevation acute coronary syndromes: a scientific statement for healthcare professionals from the American Heart Association Council on Clinical Cardiology: in collaboration with the Society of Geriatric Cardiology. Circulation 2007;115:2549-69.

2. Ortman JM, Velkoff VA, Hogan H. An aging nation: the older population in the United States. United States Census Bureau, Economics and Statistics Administration, US Department of Commerce; 2014.

3. Avezum A, Makdisse M, Spencer F, Gore JM, Fox KA, Montalescot G, Eagle KA, White K, Mehta RH, Knobel E. Impact of age on 
management and outcome of acute coronary syndrome: observations from the Global Registry of Acute Coronary Events (GRACE). Am Heart J 2005;149:67-73.

4. Aksoy S, Velibey Y, Koroglu B, Cagdas M, Guzelburc O, Cam N, Eren M. Successful primary percutaneous coronary intervention in a centenarian patient with acute myocardial infarction: online article-case report. Cardiovasc J Afr 2014;25:8-10.

5. Cloutier JM, Zieroth S, Elbarouni B. Primary percutaneous coronary intervention as treatment for ST-elevation myocardial infarction in a centenarian: choosing carefully. Can J Cardiol 2017;33:1066-e1.

6. Amsterdam EA, Wenger NK, Brindis RG, Casey DE, Ganiats TG, Holmes DR, Jaffe AS, Jneid H, Kelly RF, Kontos MC. 2014 AHA/ ACC guideline for the management of patients with non-ST-elevation acute coronary syndromes: a report of the American College of Cardiology/American Heart Association Task Force on Practice Guidelines. J Am Coll Cardiol 2014;64:e139-228.

7. Levine GN, Bates ER, Bittl JA, Brindis RG, Fihn SD, Fleisher LA, Granger CB, Lange RA, Mack MJ, Mauri L. 2016 ACC/ AHA guideline focused update on duration of dual antiplatelet therapy in patients with coronary artery disease: a report of the American College of Cardiology/American Heart Association Task Force on Clinical Practice Guidelines. J Thorac Cardiovasc Surg 2016;152:1243-75.

8. Granger CB, Goldberg RJ, Dabbous O, Pieper KS, Eagle KA, Cannon CP, Van de Werf F, Avezum A, Goodman SG, Flather MD. Predictors of hospital mortality in the global registry of acute coronary events. Arch Intern Med 2003;163:2345-53.

9. GRACE Investigators. Rationale and design of the GRACE (Global Registry of Acute Coronary Events) Project: a multinational registry of patients hospitalized with acute coronary syndromes. Am Heart J 2001;141:190-9.

10. Abu-Assi E, Ferreira-González I, Ribera A, Marsal JR, Cascant P, Heras M, Bueno H, Sánchez PL, Arós F, Marrugat J. Do GRACE (Global Registry of Acute Coronary events) risk scores still maintain their performance for predicting mortality in the era of contemporary management of acute coronary syndromes? Am Heart J 2010;160:826-34.

11. Antman EM, Cohen M, Bernink PJ, McCabe CH, Horacek T, Papuchis G, Mautner B, Corbalan R, Radley D, Braunwald E. The TIMI risk score for unstable angina/non-ST elevation MI: a method for prognostication and therapeutic decision making. JAMA 2000;284:835-42.

12. Antman EM, McCabe CH, Gurfinkel EP, Turpie AG, Bernink PJ, Salein D, de Luna AB, Fox K, Lablanche JM, Radley D. Enoxaparin prevents death and cardiac ischemic events in unstable angina/non-Q-wave myocardial infarction: results of the Thrombolysis In Myocardial Infarction (TIMI) 11B trial. Circulation 1999;100:1593-601.

13. Boersma E, Pieper KS, Steyerberg EW, Wilcox RG, Chang WC, Lee KL, Akkerhuis KM, Harrington RA, Deckers JW, Armstrong PW. Predictors of outcome in patients with acute coronary syndromes without persistent ST-segment elevation: results from an international trial of 9461 patients. Circulation 2000;101:2557-67.

14. Fried LP, Tangen CM, Walston J, Newman AB, Hirsch C, Gottdiener J, Seeman T, Tracy R, Kop WJ, Burke G. Frailty in older adults: evidence for a phenotype. J Gerontol A Biol Sci Med Sci 2001;56:M146-57.

15. Guinan P. Frailty and old age. Linacre Q 2016;83:131-3.

16. Newman AB, Gottdiener JS, McBurnie MA, Hirsch CH, Kop WJ, Tracy R, Walston JD, Fried LP. Associations of subclinical cardiovascular disease with frailty. J Gerontol A Biol Sci Med Sci 2001;56:M158-66.

17. Walston J, McBurnie MA, Newman A, Tracy RP, Kop WJ, Hirsch CH, Gottdiener J, Fried LP. Frailty and activation of the inflammation and coagulation systems with and without clinical comorbidities: results from the Cardiovascular Health Study. Arch Intern Med 2002;162:2333-41.

18. Blackwell DL, Lucas JW, Clarke TC. Summary health statistics for U.S. adults: national health interview survey, 2012. Vital Health Stat 2014;(260):1-161.

19. Hajjar ER, Hanlon JT, Sloane RJ, Lindblad CI, Pieper CF, Ruby CM, Branch LC, Schmader KE. Unnecessary drug use in frail older people at hospital discharge. J Am Geriatr Soc 2005;53:1518-23.

20. Beer C, Hyde Z, Almeida OP, Norman P, Hankey GJ, Yeap BB, Flicker L. Quality use of medicines and health outcomes among a cohort of community dwelling older men: an observational study. Br J Clin Pharmacol 2011;71:592-9.

21. Mangoni AA, Jackson SH. Age-related changes in pharmacokinetics and pharmacodynamics: basic principles and practical applications. Br J Clin Pharmacol 2004;57:6-14.

22. Khoury G, Sheikh-Taha M. Effect of age and sex on warfarin dosing. Clin Pharmacol Adv Appl 2014;6:103.

23. Moscucci M, Fox KA, Cannon CP, Klein W, López-Sendón J, Montalescot G, White K, Goldberg RJ. Predictors of major bleeding in acute coronary syndromes: the Global Registry of Acute Coronary Events (GRACE). Eur Heart J 2003;24:1815-23.

24. De Gregorio J, Kobayashi Y, Albiero R, Reimers B, Di Mario C, Finci L, Colombo A. Coronary artery stenting in the elderly: short-term outcome and long-term angiographic and clinical follow-up. J Am Coll Cardiol 1998;32:577-83.

25. Tofler GH, Massaro J, Levy D, Mittleman M, Sutherland P, Lipinska I, Muller JE, D’Agostino RB. Relation of the prothrombotic state to increasing age (from the Framingham Offspring Study). Am J Cardiol 2005;96:1280-3.

26. Knight CJ, Panesar M, Wright C, Clarke D, Butowski PS, Patel D, Patrineli A, Fox K, Goodall AH. Altered platelet function detected by flow cytometry: effects of coronary artery disease and age. Arterioscler Thromb Vasc Biol 1997;17:2044-53.

27. Becker RC. Thrombotic preparedness in aging: a translatable construct for thrombophilias? J Thromb Thrombolysis 2007;24:323-5.

28. Franchini M. Hemostasis and aging. Crit Rev Oncol Hematol 2006;60:144-51.

29. Popma JJ, Satler LF, Pichard A, Kent KM, Campbell A, Chuang YC, Clark C, Merritt AJ, Bucher TA, Leon MB. Vascular complications after balloon and new device angioplasty. Circulation 1993;88:1569-78.

30. Taddei S, Virdis A, Ghiadoni L, Salvetti G, Bernini G, Magagna A, Salvetti A. Age-related reduction of NO availability and oxidative stress in humans. Hypertension 2001;38:274-9. 
31. Batchelor WB, Anstrom KJ, Muhlbaier LH, Grosswald R, Weintraub WS, O'Neill WW, Peterson ED. Contemporary outcome trends in the elderly undergoing percutaneous coronary interventions: results in 7,472 octogenarians. J Am Coll Cardiol 2000;36:723-30.

32. Valgimigli M, Serruys PW, Tsuchida K, Vaina S, Morel MA, van den Brand MJ, Colombo A, Morice MC, Dawkins K, de Bruyne B. Cyphering the complexity of coronary artery disease using the syntax score to predict clinical outcome in patients with three-vessel lumen obstruction undergoing percutaneous coronary intervention. Am J Cardiol 2007;99:1072-81.

33. Garg S, Sarno G, Garcia-Garcia HM, Girasis C, Wykrzykowska J, Dawkins KD, Serruys PW; ARTS-II Investigators. A new tool for the risk stratification of patients with complex coronary artery disease: the Clinical SYNTAX Score. Circ Cardiovasc Interv 2010;3:317-26.

34. Scherff F, Vassalli G, Sürder D, Mantovani A, Corbacelli C, Pasotti E, Klersy C, Auricchio A, Moccetti T, Pedrazzini GB. The SYNTAX score predicts early mortality risk in the elderly with acute coronary syndrome having primary PCI. J Invasive Cardiol 2011;23:505-10.

35. Newman AB, Naydeck BL, Sutton-Tyrrell K, Feldman A, Edmundowicz D, Kuller LH. Coronary artery calcification in older adults to age 99: prevalence and risk factors. Circulation 2001;104:2679-84.

36. Raggi P, Callister TQ, Cooil B, He ZX, Lippolis NJ, Russo DJ, Zelinger A, Mahmarian JJ. Identification of patients at increased risk of first unheralded acute myocardial infarction by electron-beam computed tomography. Circulation 2000;101:850-5.

37. Bromage DI, Jones DA, Rathod KS, Grout C, Iqbal MB, Lim P, Jain A, Kalra SS, Crake T, Astroulakis Z. Outcome of 1051 octogenarian patients with ST-segment elevation myocardial infarction treated with primary percutaneous coronary intervention: observational cohort from the London Heart Attack Group. J Am Heart Assoc 2016;5:e003027.

38. Belardi J, Manoharan G, Albertal M, Widimskỳ P, Neumann FJ, Silber S, Leon MB, Saito S. The influence of age on clinical outcomes in patients treated with the resolute zotarolimus-eluting stent. Catheter Cardiovasc Interv 2016;87:253-61.

39. Antonsen L, Jensen LO, Terkelsen CJ, Tilsted HH, Junker A, Maeng M, Hansen KN, Lassen JF, Thuesen L, Thayssen P. Outcomes after primary percutaneous coronary intervention in octogenarians and nonagenarians with ST-segment elevation myocardial infarction: from the Western Denmark heart registry. Catheter Cardiovasc Interv 2013;81:912-9.

40. Hamonangan R, Wijaya IP, Setiati S, Harimurti K. Impact of frailty on the first 30 days of major cardiac events in elderly patients with coronary artery disease undergoing elective percutaneous coronary intervention. Acta Medica Indones 2016;48:91-8.

41. Spagnoli V, de Hemptinne Q, Nosair M, Gosselin G. Percutaneous coronary intervention in nonagenarians: prevalence, indications, vascular approach and mortality at 3 months. J Cardiovasc Dis Diagn 2016;4:239.

42. Kitabata H, Kubo T, Mori K, Yamamoto Y, Kashiwagi M, Arita Y, Tanimoto T, Akasaka T. Safety and efficacy outcomes of secondgeneration everolimus-eluting stents in octogenarians compared to non-octogenarians. Cardiovasc Revascularization Med Mol Interv 2018;19:12-6.

43. Caretta G, Passamonti E, Pedroni PN, Fadin BM, Galeazzi GL, Pirelli S. Outcomes and predictors of mortality among octogenarians and older with ST-segment elevation myocardial infarction treated with primary coronary angioplasty. Clin Cardiol 2014;37:523-9.

44. Higuchi S, Kabeya Y, Matsushita K, Taguchi H, Ishiguro H, Kohshoh H, Yoshino H. Barthel index as a predictor of 1-year mortality in very elderly patients who underwent percutaneous coronary intervention for acute coronary syndrome: better activities of daily living, longer life. Clin Cardiol 2016;39:83-9.

45. Lip GY, Nieuwlaat R, Pisters R, Lane DA, Crijns HJ. Refining clinical risk stratification for predicting stroke and thromboembolism in atrial fibrillation using a novel risk factor-based approach: the euro heart survey on atrial fibrillation. Chest 2010;137:263-72.

46. Sareh S, Toppen W, Mukdad L, Satou N, Shemin R, Buch E, Benharash P. CHADS2 score predicts atrial fibrillation following cardiac surgery. J Surg Res 2014;190:407-12.

47. Santana JO, Haft JI, LaMarche NS, Goldstein JE. Coronary angioplasty in patients eight years of age or older. Am Heart J 1992;124:13-8.

48. Bonnier H, de Vries C, Michels R, El Gamal M. Initial and long-term results of coronary angioplasty and coronary bypass surgery in patients of 75 or older. Heart 1993;70:122-5.

49. Tan KH, Sulke N, Taub N, Karani S, Sowton E. Percutaneous transluminal coronary angioplasty in patients 70 years of age or older: 12 years' experience. Heart 1995;74:310-7.

50. Kern MJ, Deligonul U, Galan K, Zelman R, Gabliani G, Bell ST, Bodet J, Naunheim K, Vandormael M. Percutaneous transluminal coronary angioplasty in octogenarians. Am J Cardiol 1988;61:457-8.

51. Imburgia M, King TR, Soffer AD, Rich MW, Krone RJ, Salimi A. Early results and long-term outcome of percutaneous transluminal coronary angioplasty in patients age 75 years or older. Am J Cardiol 1989;63:1127-9.

52. Jeroudi MO, Kleiman NS, Minor ST, Hess KR, Lewis JM, Winters WL, Raizner AE. Percutaneous transluminal coronary angioplasty in octogenarians. Ann Intern Med 1990;113:423-8.

53. Rich JJ, Crispino CM, Saporito JJ, Domat I, Cooper WM. Percutaneous transluminal coronary angioplasty in patients 80 years of age and older. Am J Cardiol 1990;65:675-6.

54. Johnman C, Oldroyd KG, Mackay DF, Slack R, Pell ACH, Flapan AD, Jennings KP, Eteiba H, Irving J, Pell JP. Percutaneous coronary intervention in the elderly: changes in case-mix and periprocedural outcomes in 31,758 patients treated between 2000 and 2007. Circ Cardiovasc Interv 2010;3:341-5.

55. Bogana Shanmugam V, Wong DT, Rashid H, Cameron JD, Malaiapan Y, Psaltis PJ. Bleeding outcomes after non-emergency percutaneous coronary intervention in the very elderly. J Geriatr Cardiol 2017;14:624-31.

56. Sim WL, Mutha V, Ul-Haq MA, Sasongko V, Van-Gaal W. Clinical characteristics and outcomes of octogenarians presenting with ST elevation myocardial infarction in the Australian population. World J Cardiol 2017;9:437-41.

57. Yudi MB, Hamilton G, Farouque O, Andrianopoulos N, Duffy SJ, Lefkovits J, Brennan A, Fernando D, Hiew C, Freeman M, Reid CM, Dakis R, Ajani AE, Clark DJ; Melbourne Interventional Group. Trends and impact of door-to-balloon time on clinical outcomes in patients aged $<75,75$ to 84 , and $\geq 85$ years with ST-elevation myocardial infarction. Am J Cardiol 2017;120:1245-53. 
58. Wańha W, Kawecki D, Roleder T, Morawiec B, Gładysz S, Kowalówka A, Jadczyk T, Adamus B, Pawłowski T, Smolka G, Kaźmierski M, Ochała A, Nowalany-Kozielska E, Wojakowski W. Second-generation drug-eluting stents in the elderly patients with acute coronary syndrome: the in-hospital and 12-month follow-up of the all-comer registry. Aging Clin Exp Res 2017;29:885-93.

59. Gayed M, Yadak N, Qamhia W, Daralammouri Y, Ohlow MA. Comorbidities and complications in nonagenarians undergoing coronary angiography and intervention. Int Heart J 2017;58:180-4.

60. Lahtela HM, Bah A, Kiviniemi T, Nammas W, Schlitt A, Rubboli A, Karjalainen PP, Proietti M, Hartikainen JEK, Lip GYH, Airaksinen KEJ. Outcome of octogenarians with atrial fibrillation undergoing percutaneous coronary intervention: insights from the AFCAS registry. Clin Cardiol 2017;40:1264-70.

61. Rubboli A, Schlitt A, Kiviniemi T, Biancari F, Karjalainen PP, Valencia J, Laine M, Kirchhof P, Niemelä M, Vikman S, Lip GYH, Airaksinen KEJ; AFCAS Study Group. One-year outcome of patients with atrial fibrillation undergoing coronary artery stenting: an analysis of the AFCAS registry. Clin Cardiol 2014;37:357-64.

62. Sharma R, Hiebert B, Cheung D, Jassal DS, Minhas K. Primary coronary intervention in octogenarians and nonagenarians with STsegment elevation myocardial infarction: a Canadian single-center perspective. Angiology 2017; doi: 10.1177/0003319717746520.

63. Sappa R, Grillo MT, Cinquetti M, Prati G, Spedicato L, Nucifora G, Perkan A, Zanuttini D, Sinagra G, Proclemer A. Short and longterm outcome in very old patients with ST-elevation myocardial infarction after primary percutaneous coronary intervention. Int $\mathrm{J}$ Cardiol 2017;249:112-8.

64. Bhat FA, Changal KH, Raina H, Tramboo NA, Rather HA. Transradial versus transfemoral approach for coronary angiography and angioplasty - a prospective, randomized comparison. BMC Cardiovasc Disord 2017;17:23.

65. Anjum I, Khan MA, Aadil M, Faraz A, Farooqui M, Hashmi A. Transradial vs. transfemoral approach in cardiac catheterization: a literature review. Cureus 2017;9:e1309.

66. He PY, Yang YJ, Qiao SB, Xu B, Yao M, Wu YJ, Yuan JQ, Chen J, Liu HB, Dai J, Tang XR, Wang Y, Li W, Gao RL. A comparison of transradial and transfemoral approaches for percutaneous coronary intervention in elderly patients based on a propensity score analysis. Angiology 2015;66:448-55.

67. Tammam K, Ikari Y, Yoshimachi F, Saito F, Hassan W. Impact of transradial coronary intervention on bleeding complications in octogenarians. Cardiovasc Interv Ther 2017;32:18-23.

68. Lee HW, Cha KS, Ahn J, Choi JC, Oh JH, Choi JH, Lee HC, Yun E, Jang HY, Choi JH, Hong TJ, Jeong MH, Ahn Y, Chae SC, Kim YJ; Korea Acute Myocardial Infarction Registry Investigators. Comparison of transradial and transfemoral coronary intervention in octogenarians with acute myocardial infarction. Int J Cardiol 2016;202:419-24.

69. Moses JW, Leon MB, Popma JJ, Fitzgerald PJ, Holmes DR, O’Shaughnessy C, Caputo RP, Kereiakes DJ, Williams DO, Teirstein PS, Jaeger JL, Kuntz RE; SIRIUS Investigators. Sirolimus-eluting stents versus standard stents in patients with stenosis in a native coronary artery. N Engl J Med 2003;349:1315-23.

70. Tian W, Mahmoudi M, Lhermusier T, Kiramijyan S, Chen F, Torguson R, Suddath WO, Satler LF, Pichard AD, Waksman R. The influence of advancing age on implantation of drug-eluting stents. Catheter Cardiovasc Interv 2016;88:516-21.

71. Navarese EP, Tandjung K, Claessen B, Andreotti F, Kowalewski M, Kandzari DE, Kereiakes DJ, Waksman R, Mauri L, Meredith IT, Finn AV, Kim HS, Kubica J, Suryapranata H, Aprami TM, Di Pasquale G, von Birgelen C, Kedhi E. Safety and efficacy outcomes of first and second generation durable polymer drug eluting stents and biodegradable polymer biolimus eluting stents in clinical practice: comprehensive network meta-analysis. BMJ 2013;347:f6530.

72. El-Hayek G, Messerli F, Bangalore S, Hong MK, Herzog E, Benjo A, Tamis-Holland JE. Meta-analysis of randomized clinical trials comparing short-term versus long-term dual antiplatelet therapy following drug-eluting stents. Am J Cardiol 2014;114:236-42.

73. Urban P, Meredith IT, Abizaid A, Pocock SJ, Carrié D, Naber C, Lipiecki J, Richardt G, Iñiguez A, Brunel P, Valdes-Chavarri M, Garot P, Talwar S, Berland J, Abdellaoui M, Eberli F, Oldroyd K, Zambahari R, Gregson J, Greene S, Stoll HP, Morice MC; LEADERS FREE Investigators. Polymer-free drug-coated coronary stents in patients at high bleeding risk. N Engl J Med 2015;373:2038-47.

74. Morice MC, Talwar S, Gaemperli O, Richardt G, Eberli F, Meredith I, Zaman A, Fajadet J, Copt S, Greene S, Urban P. Drug-coated versus bare-metal stents for elderly patients: a predefined sub-study of the LEADERS FREE trial. Int J Cardiol 2017;243:110-5.

75. de Belder A, de la Torre Hernandez JM, Lopez-Palop R, O'Kane P, Hernandez Hernandez F, Strange J, Gimeno F, Cotton J, Diaz Fernandez JF, Carrillo Saez P, Thomas M, Pinar E, Curzen N, Baz JA, Cooter N, Lozano I, Skipper N, Robinson D, Hildick-Smith D; XIMA Investigators. A prospective randomized trial of everolimus-eluting stents versus bare-metal stents in octogenarians: the XIMA Trial (Xience or Vision Stents for the Management of Angina in the Elderly). J Am Coll Cardiol 2014;63:1371-5.

76. Varenne O, Cook S, Sideris G, Kedev S, Cuisset T, Carrié D, Hovasse T, Garot P, El Mahmoud R, Spaulding C, Helft G, Diaz Fernandez JF, Brugaletta S, Pinar-Bermudez E, Mauri Ferre J, Commeau P, Teiger E, Bogaerts K, Sabate M, Morice MC, Sinnaeve PR; SENIOR investigators. Drug-eluting stents in elderly patients with coronary artery disease (SENIOR): a randomised single-blind trial. Lancet Lond Engl 2018;391:41-50.

77. Daugherty SL, Thompson LE, Kim S, Rao SV, Subherwal S, Tsai TT, Messenger JC, Masoudi FA. Patterns of use and comparative effectiveness of bleeding avoidance strategies in men and women following percutaneous coronary interventions: an observational study from the National Cardiovascular Data Registry. J Am Coll Cardiol 2013;61:2070-8.

78. Marso SP, Amin AP, House JA, Kennedy KF, Spertus JA, Rao SV, Cohen DJ, Messenger JC, Rumsfeld JS; National Cardiovascular Data Registry. Association between use of bleeding avoidance strategies and risk of periprocedural bleeding among patients undergoing percutaneous coronary intervention. JAMA 2010;303:2156-64.

79. Khambatta S, Othman H, Seth M, Lalonde T, Rosman HS, Gurm HS, Mehta RH; Blue Cross Blue Shield of Michigan Cardiovascular Consortium (BMC2) Investigators. Association of bleeding avoidance strategies with age-related bleeding and in-hospital mortality in 
patients undergoing percutaneous coronary interventions. Cardiovasc Revascularization Med Mol Interv 2016;17:233-40.

80. McNamara RL, Wang Y, Herrin J, Curtis JP, Bradley EH, Magid DJ, Peterson ED, Blaney M, Frederick PD, Krumholz HM; NRMI Investigators. Effect of door-to-balloon time on mortality in patients with ST-segment elevation myocardial infarction. J Am Coll Cardiol 2006;47:2180-6.

81. Yudi MB, Ramchand J, Farouque O, Andrianopoulos N, Chan W, Duffy SJ, Lefkovits J, Brennan A, Spencer R, Fernando D, Hiew C, Freeman M, Reid CM, Ajani AE, Clark DJ; Melbourne Interventional Group. Impact of door-to-balloon time on long-term mortality in high- and low-risk patients with ST-elevation myocardial infarction. Int J Cardiol 2016;224:72-8.

82. Swaminathan RV, Wang TY, Kaltenbach LA, Kim LK, Minutello RM, Bergman G, Wong SC, Feldman DN. Nonsystem reasons for delay in door-to-balloon time and associated in-hospital mortality: a report from the National Cardiovascular Data Registry. J Am Coll Cardiol 2013;61:1688-95.

83. Angeja BG, Gibson CM, Chin R, Frederick PD, Every NR, Ross AM, Stone GW, Barron HV; Participants in the National Registry of Myocardial Infarction 2-3. Predictors of door-to-balloon delay in primary angioplasty. Am J Cardiol 2002;89:1156-61.

84. Engberding N, Wenger NK. Acute coronary syndromes in the elderly. F1000Research 2017;6:1791.

85. Kim HY, Choi JH. How to utilize coronary computed tomography angiography in the treatment of coronary artery disease. J Cardiovasc Ultrasound 2015;23:204-8.

86. Karacsonyi J, Alaswad K, Jaffer FA, Yeh RW, Patel M, Bahadorani J, Karatasakis A, Danek BA, Doing A, Grantham JA, Karmpaliotis D, Moses JW, Kirtane A, Parikh M, Ali Z, Lombardi WL, Kandzari DE, Lembo N, Garcia S, Wyman MR, Alame A, Nguyen-Trong PKJ, Resendes E, Kalsaria P, Rangan BV, Ungi I, Thompson CA, Banerjee S, Brilakis ES. Use of intravascular imaging during chronic total occlusion percutaneous coronary intervention: insights from a contemporary multicenter registry. J Am Heart Assoc 2016;5:e003890.

87. Danzi GB, Campanile A, Sozzi FB, Bonanomi C. Retrograde dissection during percutaneous coronary intervention: sealing of the entry site by covered stent implantation. BMJ Case Rep 2012;2012:bcr0320126014.

88. Chen HC, Lee WC, Fu M. "Rail track picture": diagnosis of the protruding of left main coronary stent by transthoracic echocardiography especially with three-dimensional images. Eur Heart J Cardiovasc Imaging 2014;15:946.

89. Arisha MJ, Hsiung MC, Ahmad A, Nanda NC, Elkaryoni A, Mohamed AH, Yin WH. Incremental benefit of three-dimensional transesophageal echocardiography in the assessment of left main coronary artery stent protrusion. Echocardiogr Mt Kisco $\mathrm{N}$ 2017;34:915-8.

90. De Maria GL, Banning AP. Use of intravascular ultrasound imaging in percutaneous coronary intervention to treat left main coronary artery disease. Interv Cardiol Lond Engl 2017;12:8-12.

91. Terashima M, Kaneda H, Suzuki T. The role of optical coherence tomography in coronary intervention. Korean J Intern Med 2012;27:1-12.

92. Larose E, Côté J, Rodés-Cabau J, Noël B, Barbeau G, Bordeleau E, Miró S, Brochu B, Delarochellière R, Bertrand OF. Contrastenhanced cardiovascular magnetic resonance in the hyperacute phase of ST-elevation myocardial infarction. Int J Cardiovasc Imaging 2009;25:519-27.

93. Oqueli E, Dick R. Percutaneous coronary intervention in very elderly patients. In-hospital mortality and clinical outcome. Heart Lung Circ 2011;20:622-8.

94. Parikh R, Chennareddy S, Debari V, Hamdan A, Konlian D, Shamoon F, Bikkina M. Percutaneous coronary interventions in nonagenarians: in-hospital mortality and outcome at one year follow-up. Clin Cardiol 2009;32:E16-21.

95. Teplitsky I, Assali A, Lev E, Brosh D, Vaknin-Assa H, Kornowski R. Results of percutaneous coronary interventions in patients $>$ or $=90$ years of age. Catheter Cardiovasc Interv 2007;70:937-43.

96. Spoon DB, Psaltis PJ, Singh M, Holmes DR, Gersh BJ, Rihal CS, Lennon RJ, Moussa ID, Simari RD, Gulati R. Trends in cause of death after percutaneous coronary intervention. Circulation 2014;129:1286-94.

97. Peiyuan H, Jingang Y, Haiyan X, Xiaojin G, Ying X, Yuan W, Wei L, Yang W, Xinran T, Ruohua Y, Chen J, Lei S, Xuan Z, Rui F, Yunqing Y, Qiuting D, Hui S, Xinxin Y, Runlin G, Yuejin Y; CAMI Registry study group. The comparison of the outcomes between primary PCI, fibrinolysis, and no reperfusion in patients $\geq 75$ years old with ST-segment elevation myocardial infarction: results from the Chinese Acute Myocardial Infarction (CAMI) Registry. PLoS One 2016;11:e165672.

98. Global Use of Strategies to Open Occluded Coronary Arteries in Acute Coronary Syndromes (GUSTO IIb) Angioplasty Substudy Investigators. A clinical trial comparing primary coronary angioplasty with tissue plasminogen activator for acute myocardial infarction. N Engl J Med 1997;336:1621-8.

99. de Boer SPM, Westerhout CM, Simes RJ, Granger CB, Zijlstra F, Boersma E; Primary Coronary Angioplasty Versus Thrombolysis-2 (PCAT-2) Trialists Collaborators Group. Mortality and morbidity reduction by primary percutaneous coronary intervention is independent of the patient's age. JACC Cardiovasc Interv 2010;3:324-31.

100. Solhpour A, Chang KW, Balan P, Cai C, Sdringola S, Denktas AE, Smalling RW, Anderson HV. Comparison of outcomes for patients $\geq 75$ years of age treated with pre-hospital reduced-dose fibrinolysis followed by percutaneous coronary intervention versus percutaneous coronary intervention alone for treatment of ST-elevation myocardial infarction. Am J Cardiol 2014;113:60-3.

101. Nicolini F, Contini GA, Fortuna D, Pacini D, Gabbieri D, Vignali L, Campo G, Manari A, Zussa C, Guastaroba P, De Palma R, Gherli T. Coronary artery surgery versus percutaneous coronary intervention in octogenarians: long-term results. Ann Thorac Surg 2015;99:567-74.

102. Sheridan BC, Stearns SC, Rossi JS, D’Arcy LP, Federspiel JJ, Carey TS. Three-year outcomes of multivessel revascularization in very elderly acute coronary syndrome patients. Ann Thorac Surg 2010;89:1889-94; discussion 1894-5.

103. Levine GN, Bates ER, Blankenship JC, Bailey SR, Bittl JA, Cercek B, Chambers CE, Ellis SG, Guyton RA, Hollenberg SM, Khot UN, 
Lange RA, Mauri L, Mehran R, Moussa ID, Mukherjee D, Nallamothu BK, Ting HH; American College of Cardiology Foundation, American Heart Association Task Force on Practice Guidelines, Society for Cardiovascular Angiography and Interventions. 2011 ACCF/AHA/SCAI Guideline for percutaneous coronary intervention. A report of the American College of Cardiology Foundation/ American Heart Association Task Force on Practice Guidelines and the Society for Cardiovascular Angiography and Interventions. J Am Coll Cardiol 2011;58:e44-122.

104. Ibanez B, James S, Agewall S, Antunes MJ, Bucciarelli-Ducci C, Bueno H, Caforio ALP, Crea F, Goudevenos JA, Halvorsen S, Hindricks G, Kastrati A, Lenzen MJ, Prescott E, Roffi M, Valgimigli M, Varenhorst C, Vranckx P, Widimský P; ESC Scientific Document Group. 2017 ESC Guidelines for the management of acute myocardial infarction in patients presenting with ST-segment elevation: the task force for the management of acute myocardial infarction in patients presenting with ST-segment elevation of the European Society of Cardiology (ESC). Eur Heart J 2018;39:119-77. 